\title{
Personalized therapy: CNS HGNET-BCOR responsiveness to arsenic trioxide combined with radiotherapy
}

\author{
Claudia Paret $1,14, *$, Alexandra Russo ${ }^{1,14, *}$, Henrike Otto ${ }^{1,14}$, Arnulf Mayer ${ }^{2}$, Sebastian \\ Zahnreich $^{2}$, Wolfgang Wagner ${ }^{3}$, David Samuel ${ }^{4}$, David Scharnhorst ${ }^{5}$, David A. \\ Solomon $^{6}$, Girish Dhall7, Kenneth Wong ${ }^{8}$, Hannah Bender ${ }^{1}$, Francesca Alt ${ }^{1,14}$, Arthur \\ Wingerter $^{1,14}$, Marie A. Neu ${ }^{1,14}$, Olaf Beck ${ }^{1,14}$, Dirk Prawitt ${ }^{9}$, Stefan Eder ${ }^{1,14}$, Nicole \\ Henninger ${ }^{1,14}$, Khalifa El Malki ${ }^{1,14}$, Nadine Lehmann ${ }^{1,14}$, Nora Backes ${ }^{1,14}$, Lea Roth ${ }^{1,14}$, \\ Larissa Seidmann ${ }^{10}$, Clemens Sommer ${ }^{11}$, Marc A. Brockmann ${ }^{12}$, Gundula Staatz ${ }^{13}$, \\ Heinz Schmidberger ${ }^{2}$ and Jörg Faber ${ }^{1,14}$

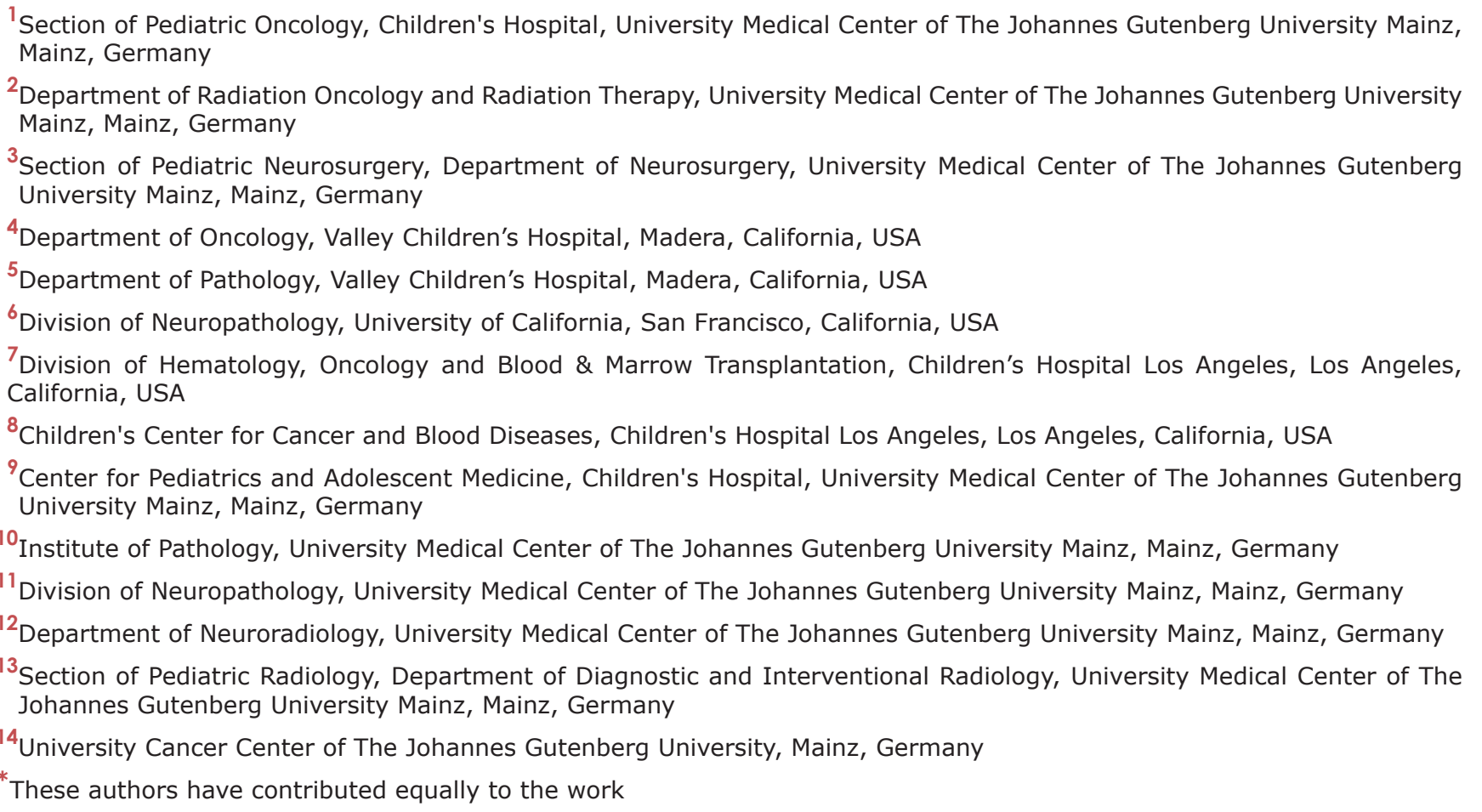 \\ Correspondence to: Claudia Paret, email: claudia.paret@unimedizin-mainz.de
}

Keywords: ATO; HGNET-BCOR; radiation; liquid biopsy; targeted therapy

Received: August 09, $2017 \quad$ Accepted: November 16, $2017 \quad$ Published: December 11, 2017

Copyright: Paret et al. This is an open-access article distributed under the terms of the Creative Commons Attribution License 3.0 (CC BY 3.0), which permits unrestricted use, distribution, and reproduction in any medium, provided the original author and source are credited.

\section{ABSTRACT}

High-grade neuroepithelial tumor of the central nervous system with BCOR alteration (HGNET-BCOR) is a rare, highly malignant tumor. At the time of this publication, no standard protocol exists to treat this tumor entity. In this work, we tested the responsiveness of the primary culture PhKh1 derived from tumor tissue from a pediatric HGNET-BCOR patient (P1) to inhibitors of the Sonic hedgehog pathway combined with radiation. The SMO inhibitors vismodegib and itraconazole had low effect on the proliferation of the PhKh1 cells. However, the GLI inhibitor arsenic trioxide reduced the expression of GLI target genes in the PhKh1 cells and in combination with radiotherapy significantly decreased their clonogenic potential. 


\begin{abstract}
PhKh1 cells resistant to arsenic trioxide were characterized by the overexpression of molecular chaperones. We combined arsenic trioxide and radiation in the relapse therapy protocol of P1, achieving complete remission after seven weeks. Clinical remission lasted for six months, when $\mathrm{P} 1$ developed systemic metastases. Meanwhile, an increase in the concentration of circulating tumor DNA carrying a BCOR internal tandem duplication was observed. Molecular characterization of a second patient (P2) was also performed. In P2, we detected a larger tandem duplication and greater activation of the Sonic hedgehog pathway than in P1. These findings suggest that combining arsenic trioxide with radiotherapy may represent a new therapeutic approach. Moreover, peripheral blood analysis for circulating tumor DNA could help in the early detection of systemic metastases.
\end{abstract}

\section{INTRODUCTION}

High-grade neuroepithelial tumor of the central nervous system with BCOR gene alteration (CNS HGNET-BCOR) is a rare entity described first in 2016 affecting particularly children [1]. HGNET-BCOR represents $3 \%$ of tumors with an institutional diagnosis of "CNS-PNET" according to the old World Health Organization diagnostic lexicon. HGNET-BCOR is characterized by somatic internal tandem duplication (ITD) in the C-terminus of BCL-6 co-repressor (BCOR) associated with an upregulation of $B C O R$ expression. The same duplication has been also described in clear cell sarcoma of the kidney [2], soft tissue undifferentiated round cell sarcoma of infancy (URCSI) and primitive myxoid mesenchymal tumor of infancy (PMMTI) [3]. Preliminary survival data suggest that the CNS HGNETBCOR entity has poor overall survival with most patients experiencing disease progression within the first year of diagnosis. Thus, new treatment options are highly warranted.

We and other have recently demonstrated the activation of the Sonic hedgehog (SHH) pathway in CNS HGNET-BCOR $[1,4]$. The binding of the SHH ligand to the Patched-1 (PTCH1) receptor relieves smoothened (SMO) inhibition, leading to activation of gliomaassociated oncogene (GLI) transcription factors (GLI1-3). Activated GLIs accumulate in the nucleus and controls the transcription of SHH target genes supporting cell proliferation. While GLI activation may result from $\mathrm{SHH}$ ligand-induced signaling, there is mounting evidence for non-canonical signaling leading to the expression of GLI proteins [5].

The SMO and the GLI family of zinc-finger transcription factors are considered important targets for cancer therapeutics. The SMO inhibitor vismodegib has already been approved by the FDA for the treatment of basal cell carcinoma [6]. We previously have shown that a primary CNS HGNET-BCOR cell culture (PhKh1) is sensitive to arsenic trioxide (ATO) [4], a drug known to target the SHH pathway at the level of GLI proteins [7]. ATO is a FDA-approved drug used for the treatment of acute promyelocytic leukemia (APL), including pediatric patients [8].
In this study, we applied the concept of personalized therapy to a pediatric patient (P1) with a diagnosis of CNS HGNET-BCOR and upregulation of the SHH pathway. First, we tested several SHH pathway inhibitors on the tumor cells of the patient in vitro. Then, we showed a relationship between the dose of radiation and control of tumor growth. Based on these results, we developed a personalized treatment protocol for the patient which comprised of ATO and radiation and measured serum and cerebrospinal fluid (CSF) ATO concentrations. Finally, we monitored the tumor status through the analysis of the circulating DNA (ctDNA) in peripheral blood. We also report a second pediatric patient (P2) with CNS HGNET-BCOR where we were able to confirm activation of the SHH pathway at a higher level than in the first patient. The ITD of BCOR in P2 was also found to be longer compared to P1.

\section{RESULTS}

\section{PhKh1 cells are more sensitive to GLI than to SMO inhibition}

We incubated the PhKh1 primary cells with different concentrations of vismodegib and itraconazole (Figure 1A and 1B), two drugs known to inhibit the SMO receptor with different mechanisms of action [9]. The $\mathrm{IC}_{50}$ of itraconazole was $15 \mu \mathrm{M}$ and of vismodegib was $40 \mu \mathrm{M}$. Lower $\mathrm{IC}_{50}$ values of about $55 \mathrm{nM}$ and $8 \mu \mathrm{M}$ have been described for itraconazole- and vismodegibsensitive cells, respectively $[10,11]$. We previously have shown that PhKh1 cells are sensitive to the GLI inhibitor ATO with an $\mathrm{IC}_{50}$ of $1.5 \mu \mathrm{M}$. Whereas many traditional chemotherapeutics inhibit proliferation on the timeframe of hours or in a few days of treatment, targeted therapies that affect cancer-relevant pathways can require several days to impact cellular growth and survival. To study the long-term effect of GLI and SMO inhibition, we incubated the PhKh1 cells with ATO, vismodegib or itraconazole for nine days (Figure 1C). Itraconazole at $15 \mu \mathrm{M}$ had no influence on long term cell proliferation. Vismodegib at $40 \mu \mathrm{M}$ significantly reduced cell proliferation but not as efficiently as ATO at $1.5 \mu \mathrm{M}$. ATO at $3 \mu \mathrm{M}$ completely inhibited cell growth. Thus, a lower concentration of ATO than of vismodegib is required to reduce cell growth. 
Mutations in SMO have been described as a mechanism of resistance to the SMO inhibitor vismodegib [11]. We have previously described that the primary tumor and the metastases of P1 did not carry SMO missense mutations [4]. Here we extended the analysis to the PhKh1 primary cells. By Sanger sequencing we didn't find any mutation changing the protein sequence of SMO (data not shown). These data suggest that the low sensitivity of the PhKh1 cells to SMO inhibition is not dependent on SMO alterations.

To exclude that a loss of the expression of the $\mathrm{SHH}$ ligand in the cell culture system could account for the reduced sensitivity to SMO specific inhibition, we analyzed the expression of the $S H H$ ligand by qRT-PCR in $\mathrm{P} 1$. The $S H H$ ligand was highly expressed in the primary tumor, in a metastasis and in the PhKh1 cells, but not in a medulloblastoma tissue of the WNT subtype (Figure 1D). These data indicate that the expression of the $\mathrm{SHH}$ ligand is maintained in the cell culture system.

To further understand the mechanism of action of ATO, we analyzed the expression of the GLI target genes GLI1, GLI2 and PTCH1 after incubation with $1 \mu \mathrm{M}$ ATO (Figure 1E). The expression of GLI1, GLI2 and PTCH1 was circa $49 \%, 81 \%$, and $46 \%$ of the control, respectively. These results suggest that ATO decreases the expression of target genes of the SHH pathway, thus inhibiting cell proliferation.

In summary, these results suggest a partially SMO-independent GLI transcriptional activity that can be inhibited by ATO in vitro. The inhibition of the $\mathrm{SHH}$ pathway can be monitored by the reduction in the expression of the $\mathrm{SHH}$ target genes and correlates with the anti-proliferative potential of ATO in long-term experiments. An ATO concentration of $3 \mu \mathrm{M}$ was required to fully block the growth of the PhKh1 cells in long-term experiments. This concentration is achievable in clinical setting [12].

\section{Resistance to ATO is characterized by the up-regulation of transcripts coding for stress proteins}

If PhKhl cells were grown under $1 \mu \mathrm{M}$ ATO, resistant clones inevitably grew. To understand the mechanisms of resistance, we performed transcriptome analysis of the PhKh1 cells grown under $1 \mu \mathrm{M}$ ATO or under vehicle alone. Eight genes were highly upregulated in the resistance cells compared to control (Table 1). Of these, ANXA1, CLU, SLC17A1 and RCAN1 encode for stress proteins [13-16]. ANXA1, ANXA3, CLU and CTGF are associated with drug resistance [17-20]. Interestingly, upregulation of cell migration-inducing protein (CEMIP) has been associated with enhanced cell migration [21]. These data indicate that ATO induces the expression of proteins that may allow the cellular recovery from stress, thus restoring protein homeostasis and promoting cell survival. Co-targeting these stressinduced survival pathways may better manipulate cancer cell sensitivity to ATO therapy.

\section{ATO causes additive cytotoxicity to ionizing radiation in PhKh1 cells}

As fractionated radiation therapy is central to the treatment of high-grade central nervous system tumors, we measured the in vitro clonogenic survival of PhKh1 cells after X-ray exposure with or without concomitant ATO treatment. Figure 2 shows the respective radiation dose-response survival curves. Treatment of $\mathrm{PhKh} 1$ cells with $0.5 \mu \mathrm{M}$ ATO alone reduced the clonogenic survival to about $10 \%$ of untreated cells. Treatment just with ionizing radiation reduced the viability of PhKh1 cells in a dose-dependent manner. Concomitant radiation and ATO significantly reduced the clonogenic survival compared to radiation alone by additive cytotoxicity.

\section{HGNET-BCOR response to irradiation}

The primary tumor of P1 was localized to the right parieto-occipital lobe [4]. The first line therapy of P1 included irradiation based on the HIT-HGG protocol and maintenance therapy based on the HIT-MED protocol (Figure 3 ) but the P1 developed three metastatic lesions to the skull during maintenance chemotherapy. All three metastatic lesions were located close to the area of the former resection cavity, suggesting that the tumor cells were displaced from the primary tumor during the initial resection. Detailed review of the irradiation field indicated that all three metastases arose outside of the high-dose irradiation area (Figure 4A). In parallel with the skull metastases, a newly formed dural lesion was also detected at the supero-lateral margin of the former resection cavity to the right parieto-occipital lobe (Figure 4B, circle). The dural lesion received 59.4 Gy in the first irradiation. We used this metastatic dural lesion as a measurable disease to monitor subsequent response to the personalize target therapy described below.

\section{Personalized therapy of P1}

Macroscopic complete resection of the skull metastases was performed. Local and reference pathology laboratory analysis of these tissues samples revealed the same tumor entity. Our relapse treatment protocol combined conventional radio-chemotherapy with an individualized therapy approach based on our molecular characterization of the tumor (Figure 3). As a back-bone of chemotherapy, we integrated treatment elements from pediatric rhabdoid and soft-tissue sarcoma protocol (EURHAB; CWS-Register "SoTiSaR", Soft Tissue Sarcoma Registry) based on the scientific rationale that GLI overexpression has been also detected in pediatric 
A

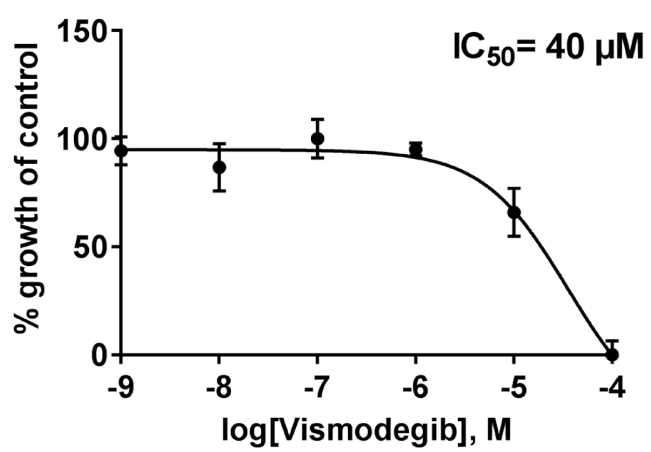

C

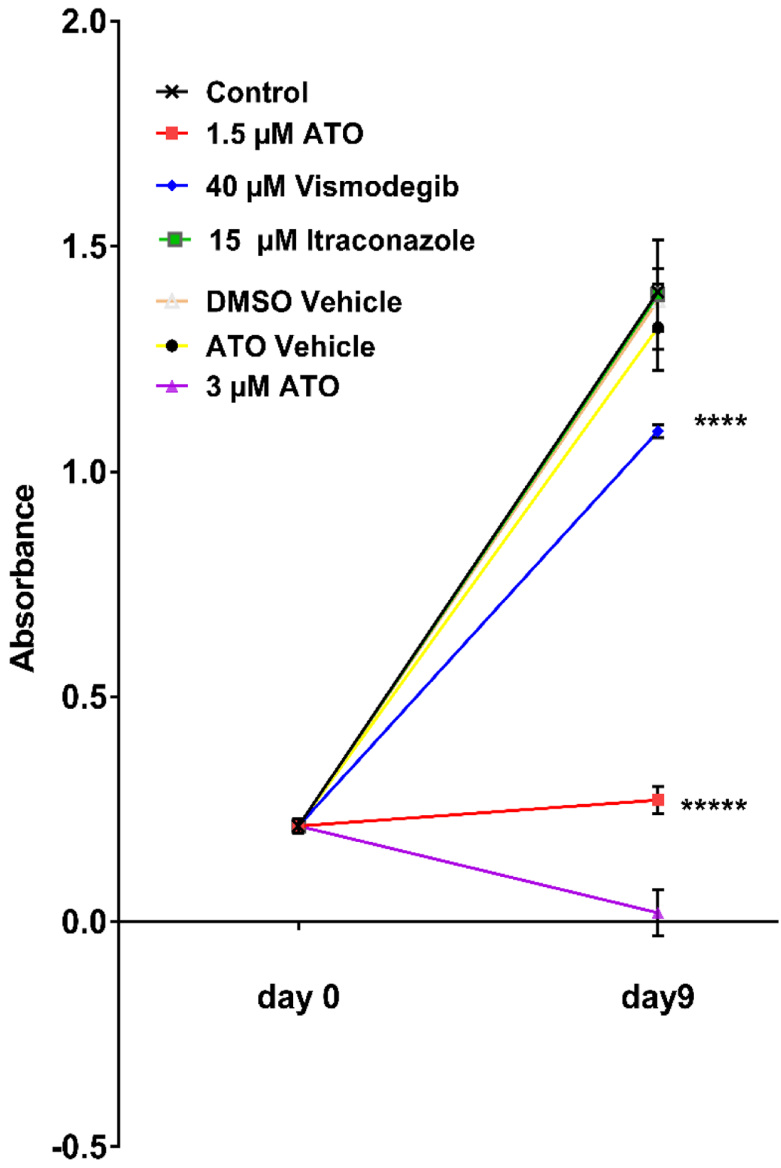

B

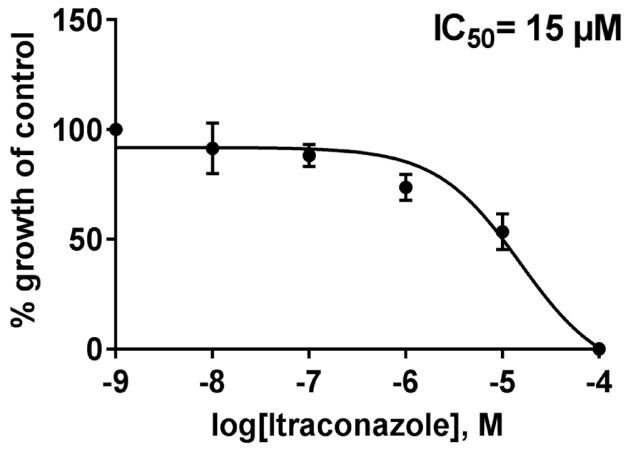

D

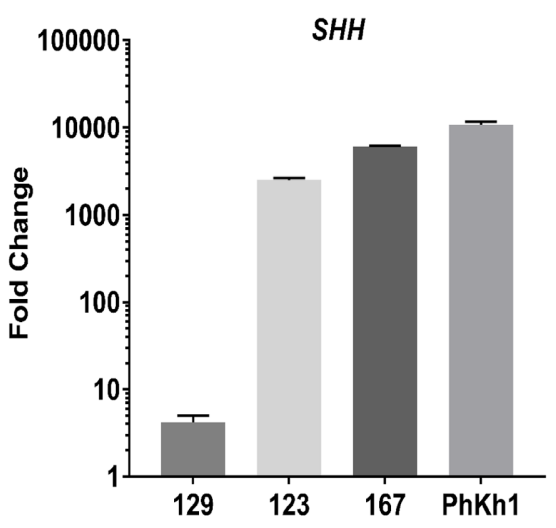

E

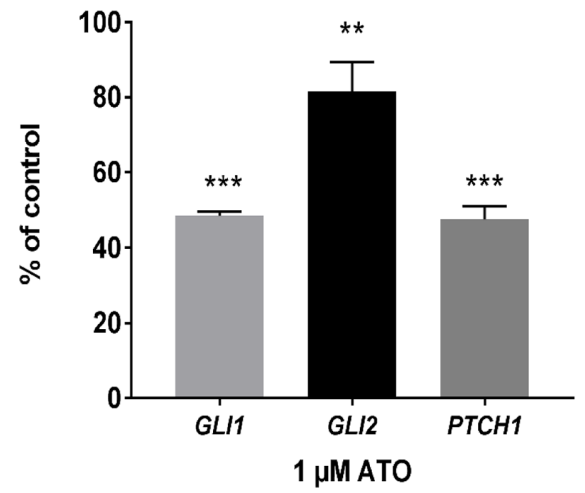

Figure 1: PhKh1 cells are more sensitive to GLI than to SMO inhibition. (A-B) PhKh1 cells were treated with vismodegib or itraconazole at doses from $1 \mathrm{nM}$ to $100 \mu \mathrm{M}$. The logarithm of the molarity is displayed on the $\mathrm{X}$-axis. The percent of viable cells compared to the control treated with vehicle alone is shown on the Y-axis. The data were fitted to a sigmoidal dose-response curve using GraphPad software. A representative experiment of three independent experiments is shown. (C) The PhKh1 cells were grown for nine days in the presence of ATO, itraconazole, vismodegib or vehicle alone at the indicated concentrations. The absorbance after incubation with the WST1 reagent is indicated. Statistics were performed using student's t-test at day 9 compared to the control: ${ }^{* * * *} \mathrm{p}<0.0001,{ }^{* * * * *} \mathrm{p}<0.00001$. (D) The expression of the $S H H$ ligand was analyzed by qRT-PCR in normal brain, the primary HGNET-BCOR tumor (no 123), a metastasis of HGNET-BCOR (no 167), a medulloblastoma of the WNT subtype (no 129) and the PhKh1 cells. The fold change of the expression with respect to normal brain is shown. (E) PhKh1 cells were incubated for 18 hours with $1 \mu \mathrm{M}$ ATO or vehicle alone. After RNA extraction, qRTPCR analysis of GLII GLI2 and PTCH1 was performed. The expression in the ATO-treated cells is shown as percent of the expression in the vehicle-treated cells. Expression analysis was done in triplicates. Statistics were performed using student's t-test: ${ }^{* * *} p=0.001,{ }^{* *} p=0.0056$. 
Table 1: Transcripts upregulated in the ATO resistant cells

\begin{tabular}{|c|c|c|c|c|c|}
\hline Gene & Entrez gene name & Expr fold change & TPM_control & TPM_ATO & Location \\
\hline CTGF & $\begin{array}{l}\text { connective tissue growth } \\
\text { factor }\end{array}$ & 98.309 & 5.803 & 570.486 & Extracellular Space \\
\hline ANXA1 & annexin A1 & 63.838 & 5.192 & 331.465 & Plasma Membrane \\
\hline RCAN1 & regulator of calcineurin 1 & 61.117 & 25.688 & 1569.973 & Nucleus \\
\hline ANXA3 & annexin $\mathrm{A} 3$ & 55.225 & 1.181 & 65.216 & Cytoplasm \\
\hline SMN2 & $\begin{array}{c}\text { survival of motor neuron } 1 . \\
\text { telomeric }\end{array}$ & 35.726 & 1.000 & 35.726 & Nucleus \\
\hline SLC7A11 & $\begin{array}{c}\text { solute carrier family } 7 \\
\text { member } 11\end{array}$ & 23.848 & 1.000 & 23.848 & Plasma Membrane \\
\hline CEMIP & $\begin{array}{l}\text { cell migration inducing } \\
\text { hyaluronan binding protein }\end{array}$ & 22.876 & 4.328 & 99.020 & Cytoplasm \\
\hline CLU & clusterin & 20.445 & 9.577 & 176.646 & Cytoplasm \\
\hline
\end{tabular}

The Expr fold change indicates the ratio between the TPMs of PhKh1 cells grown under ATO (TPM_ATO) and the TPMs of the PhKh1 cells grown under vehicle alone (TPM control). The location of the corresponding proteins are also indicated.

rhabdoid tumors as well as in several sarcoma cell types [22-24]. Chemotherapy incorporated ifosfamide, carboplatin, etoposide regimen (ICE), ifosfamide, vincristine, dactinomycin $\mathrm{C}\left(\mathrm{I}^{2} \mathrm{VAd}\right)$ regimen and doxorubicin (DOX).

Due to the noted radiosensitivity of the tumor, reirradiation with 44 Gy ( 5 x 2 Gy/week) of the former position of the metastatic skull lesions was performed (high parietal/frontal and occipital) (Figure 4C and 4D). Reirradiation was done with $3 \mathrm{~cm}$ safety margin and included the newly formed dural lesion which was re-irradiated to 44 Gy (Figure 4D, circle). ATO was administered to coincide with the last two weeks of radiation. To reach therapeutically meaningful concentrations, we chose a dose $0.05 \mathrm{mg} / \mathrm{kg}$ higher than the dose recommended for the treatment of pediatric patients with promyelocytic leukemia [8]. We conducted two cycles of intravenous ATO $(0.2 \mathrm{mg} / \mathrm{kg})$, given five days per week for six weeks in the first cycle (ATO I) and for four weeks in the second cycle (ATO II) with an interval of eight weeks in between. To avoid electrolyte disturbances serum electrolytes were closely monitored throughout treatment with ATO and potassium supplements given as needed. Electrocardiograms were monitored before the start of ATO and then weekly during treatment to evaluate for possible QT prolongation, a known side effect of ATO. The concomitant treatment with ATO and radiotherapy did not increase adverse effects in $\mathrm{P} 1$, in keeping with previous reports in pediatric patients [25].

Radiographic follow-up using magnetic resonance imaging (MRI) revealed a continuous treatment response with the patient achieving complete remission (CR) with no measurable disease activity seven weeks after the initiation of relapse therapy (calculated starting from the first ICE block) including four weeks of targeted therapy with intravenous ATO (Figure 5A-5D). CR was confirmed by a further MRI nearly two months later. Five months after the initiation of the relapse therapy (and 6 months after the resection of the metastases) the patient developed cranial and extra cranial metastases in lung, liver, spinal column and bones (Supplementary Figure 1). Notably, the former site of relapse in the skull was not involved.

Following the diagnosis of progressive, systemic disease, we switched to an oral ATO formulation in order to forgo hospitalization of the patient. To increase the plasma arsenic concentration, we extended the oral formula dosage of ATO to $0.3 \mathrm{mg} / \mathrm{kg}$ (ATO III). The oral ATO formulation was prepared in our hospital pharmacy based on the publication of Kumana et al. [26]. The administration of parenteral ATO is well established in the therapy of acute promyelocytic leukemia (APL) and the oral formulation of ATO appears to have a comparable efficiency $[26,27]$ although, the clinical use of oral ATO in pediatric patients is less common. ATO was well tolerated intravenously and orally. No adverse cardiac effects, in particular, QT prolongation [28] or any skin reactions were observed. Furthermore, P1 did not develop any electrolyte disturbances with oral substitution of potassium. The oral ATO was given continuously for a period of four weeks. Due to the highly malignant nature of the disease, P1 died 22 months after initial diagnosis and 10 months after relapse.

\section{The concentration of arsenic in plasma and CSF samples of $\mathrm{P} 1$ didn't reach the $\mathrm{IC}_{50}$}

The total amount of arsenic at the end of each cycle was $48.3 \mu \mathrm{g} / \mathrm{l}$ (ATO I) and $46.9 \mu \mathrm{g} / \mathrm{l}$ (ATO II) in plasma 
and $9.1 \mu \mathrm{g} / 1$ (ATO I) and $6.5 \mu \mathrm{g} / 1$ (ATO II) in CSF. After 2 weeks of ATO III, the concentration was $45.3 \mu \mathrm{g} / 1$ in plasma and $9.7 \mu \mathrm{g} / \mathrm{l}$ in CSF. In accordance with several reports [29], we observed a linear correlation $(r=0.854$; $\mathrm{p}<0.05$ ) between the two compartments, with CSF levels at $16.5 \%$ of the plasma level. This was equivalent with a plasma/CSF ratio around 6:1. Regarding the systemic bioavailability of ATO, parenteral and enteral administration provided comparable concentrations in the plasma and CSF compartements. These results coincide with findings from adult APL patients treated with intravenous and oral ATO [26]. In conclusion, the maximal arsenic concentration achieved in P1 was of 48.3 $\mu \mathrm{g} / \mathrm{l}$ in plasma and of $9.7 \mu \mathrm{g} / \mathrm{l}$ in CSF corresponding to a maximum arsenic concentration of $645 \mathrm{nM}$ and $129 \mathrm{nM}$ respectively, a concentration that was below the $\mathrm{IC}_{50}$.

\section{The BCOR ITD is maintained in the systemic metastases}

Because tissue biopsies of the systemic metastases at the time of the second relapse were not performed, we used peripheral blood to monitor the tumor status in $\mathrm{P} 1$, especially the persistence of the BCOR ITD under the targeted therapy. First we established primers for the detection of the BCOR ITD. The sequence of the $B C O R$ ITD of P1 has been already described [4]. The primers detected the BCOR ITD in the genomic DNA extracted from the primary tumor and a metastasis from P1 but not the $B C O R$ wild type (wt) in the genomic DNA extracted from the blood of P1 (Figure 6A) and had an efficiency of $100 \%$ (Figure 6B). We extracted the ctDNA from four samples of peripheral blood at different points of time after the detection of CR by MRI. One sample was collected 24 days after the radiographic detection of $\mathrm{CR}$ and three further samples were collected prior to the radiographic appearance of systemic metastatic disease. The concentration of the ctDNA ranged from $0.338 \mathrm{ng} / \mu \mathrm{l}$ to $5.820 \mathrm{ng} / \mu \mathrm{l}$. The ctDNA was highly fragmented as expected [30] with a median size of about 160 bps (Figure 6C). Twenty-four days after the $\mathrm{CR}$, the concentration of the BCOR ITD was at the limit of detection of our assay (Figure 6D). After circa two months, a clear increase in the concentration of the BCOR ITD was detectable and reached the maximum four days before the radiographic detection of the systemic metastases by MRI (Figure 6D, day 108). These data indicate that the BCOR ITD is still present in the lesions that developed after the systemic spread of the disease and that the liquid biopsy of peripheral blood represents a powerful method for the early detection of systemic metastasis in these patients.

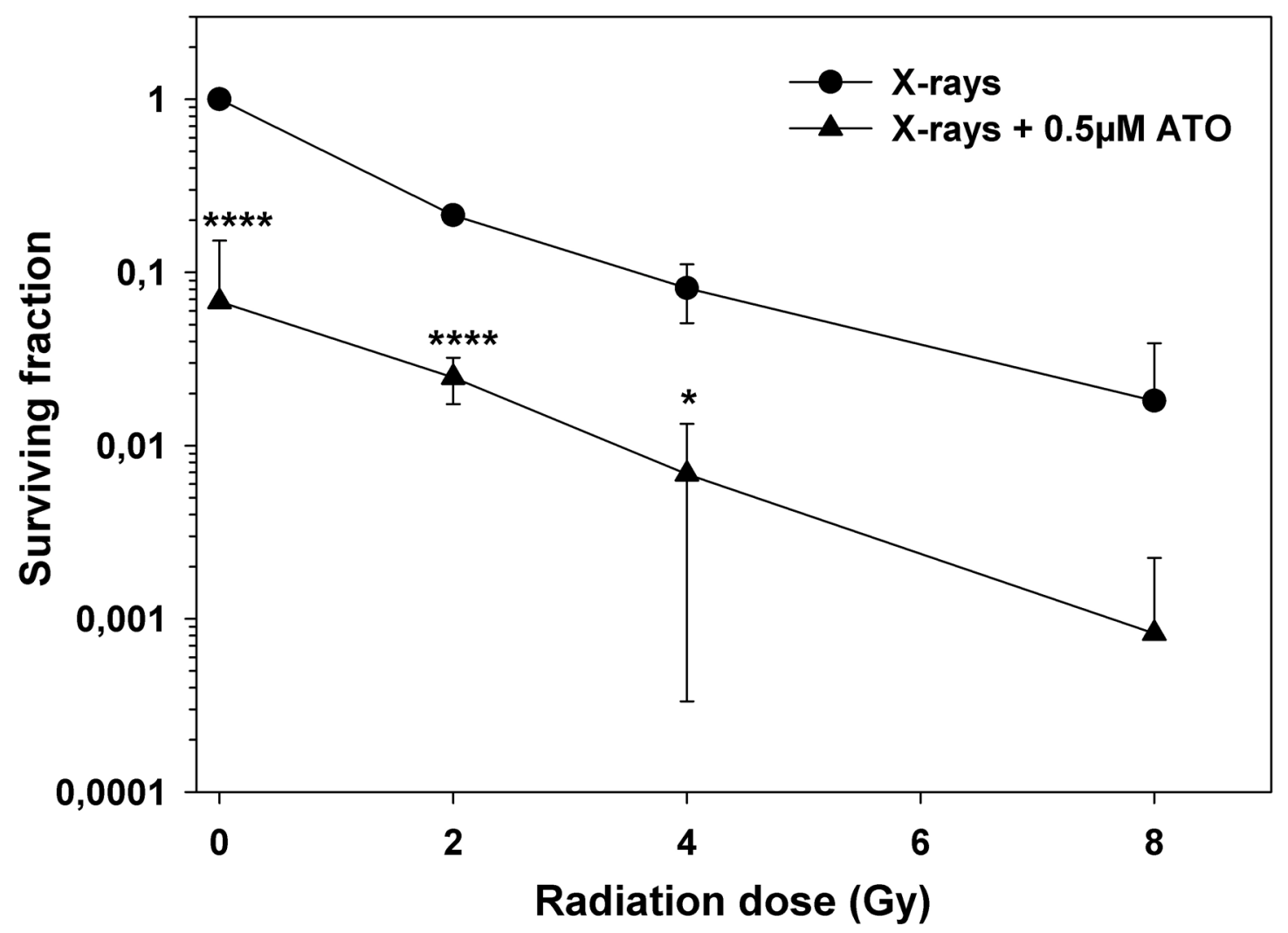

Figure 2: Additive cytotoxicity of radiation and ATO in PhKh1 cells. Dose-response survival curves of PhKh1 cells after exposure to X-rays with or without ATO. Data are shown as the mean \pm standard deviation from three independent experiments. Lines are drawn to guide the eye. All data were normalized to non-irradiated cells without ATO. Statistics were performed using student's t-test: ${ }^{*} \mathrm{p}<0.05,{ }^{* * * *} \mathrm{p}<0.0001$. 


\section{The SHH pathway is upregulated in a second CNS HGNET-BCOR patient (P2)}

CNS HGNET-BCOR is characterized by tandem duplication in exon 15 of the BCOR gene. This tandem duplication can be of different sizes. We analyzed exon 15 in the genomic DNA extracted from the blood and the primary tumor of $\mathrm{P} 1$ and from the primary tumor of $\mathrm{P} 2$ by PCR (Figure 7A). Only the BCOR wt could be detected in the blood of P1, only the $B C O R$ ITD could be detected in the tumor of P1 and the wt and the BCOR ITD could be both detected in the tumor of P2. This can be explained by the fact that $B C O R$ is located on the $\mathrm{X}$ chromosome and therefore male individuals carry only one allele. We cloned and sequenced the BCOR ITD in P2 revealing an internal tandem duplication of 126 nucleotides (42 amino acids) (Figure 7B). If the presence of the wt $B C O R$ allele in female patients can influence the severity of the disease remains to be elucidate. The insertion in P2 is larger than that detected in P1 and is one of the largest described at the time of this publication [1]. The ITD of P2 and P1 are both localized in a domain required for the binding of BCOR to a Polycomb proteins complex [31]. We validated the upregulation of the SHH pathway in $\mathrm{P} 2$ by qRT-PCR. Expression of $B C O R$ in $\mathrm{P} 2$ was even stronger than in $\mathrm{P} 1$
(Figure 7C). To functionally validate the activation of the SHH pathway, we analyzed the expression of GLI1, GLI2 and PTCH1. All three genes were highly expressed in P2, even stronger than in P1. These results confirm the assumption that the upregulation of the SHH pathway is a common feature of HGNET-BCOR. However, while the expression of GLI2 was confirmed at the protein level in tumor material extracted from P1 (Supplementary Figure 2 ), no fresh frozen material was available to perform the analysis in P2 and we cannot conclude if the higher RNA expression in $\mathrm{P} 2$ corresponds to a higher protein expression.

Treatment of P2 was given according to the Children's Oncology Group ACNS 0334 protocol, in an attempt to delay or avoid radiotherapy [32-34]. Therapy consisted of three induction cycles of chemotherapy, including high-dose methotrexate, and three consolidation cycles of myeloablative chemotherapy with autologous hematopoietic stem cell rescue. However, as more information on the propensity of this tumor entity to relapse became available, a decision to treat with lowdose craniospinal irradiation (18 Gy) and tumor bed boost (54 Gy) was made. Treatment details of P2 can be found in the Supplementary Materials. To date, 20 months from diagnosis and 10 months from completing treatment, the patient remains in clinical and radiological remission.

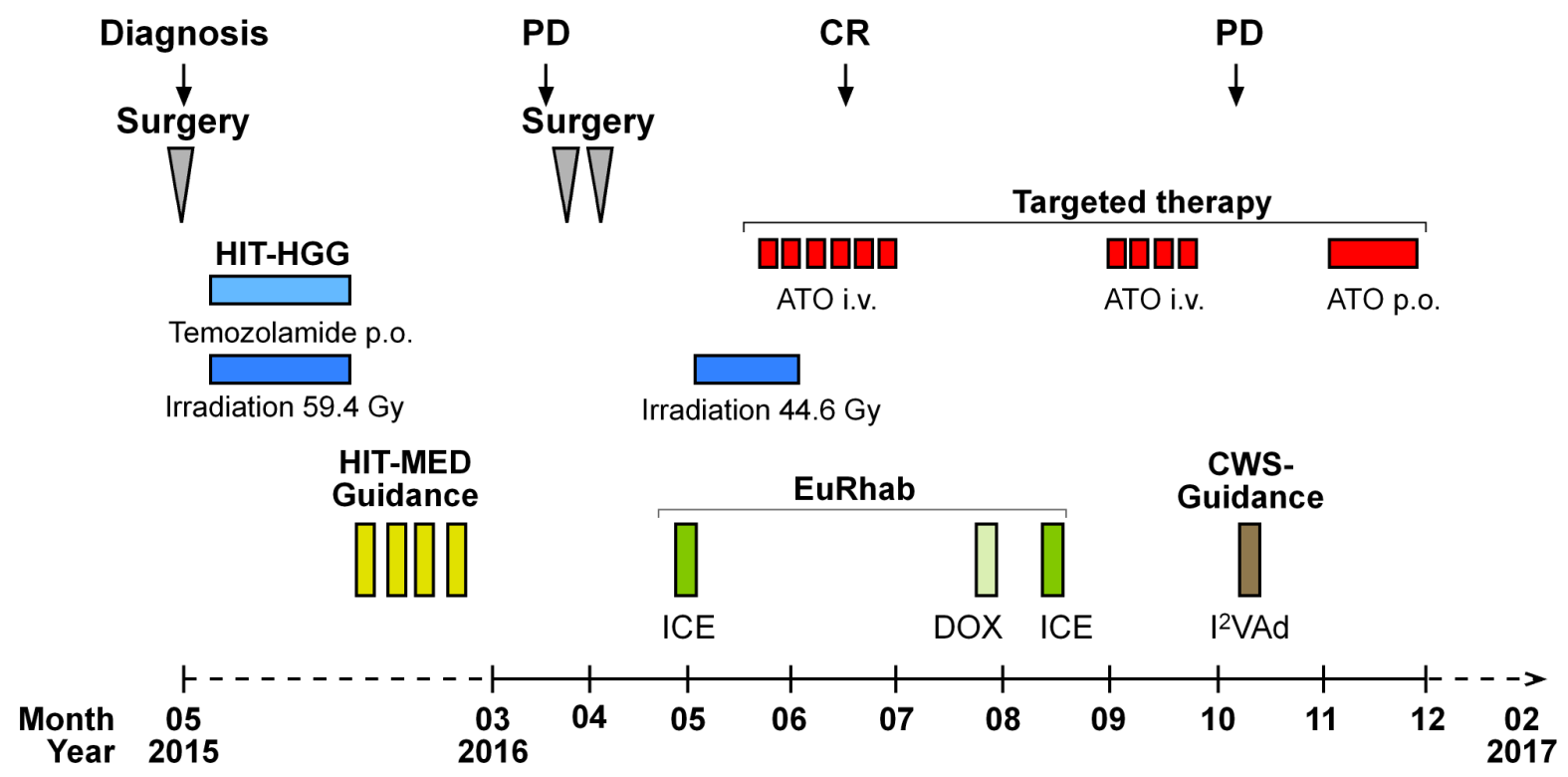

Figure 3: Therapy of P1. With a presumed diagnosis of a malignant glioma, we initiated treatment according to the HIT-HGG protocol (cranial irradiation with $59.4 \mathrm{~Gy}$ in 30 fractions with concomitant oral temozolamide chemotherapy). Due to the following diagnosis of a "primitive neuroectodermal tumor with WNT-like subtype" we added 4 cycles of chemotherapy with vincristine, cisplatin and CCNU according to the HIT-Med protocol. The relapse treatment protocol combined conventional radio-chemotherapy with an individualized therapy approach. The back-bone chemotherapy, included elements from pediatric rhabdoid and soft-tissue sarcoma protocol (EURHAB; CWS-Register "SoTiSaR", Soft Tissue Sarcoma Registry). After surgical resection, the sites of the metastatic skull lesions were irradiated with $44 \mathrm{~Gy}(5 \mathrm{x} 2 \mathrm{~Gy} /$ week). ATO was administered to coincide with the last two weeks of radiation. We conducted two cycles of intravenous (i.v.) ATO, given five days per week for six weeks in the first cycle (ATO I) and for four weeks in the second cycle (ATO II) with an interval of eight weeks in between. Following the diagnosis of progressive, systemic disease, we switched to an oral (p.o.) ATO formulation for four weeks. PD and CR were assessed by MRI. PD = progressive disease; $\mathrm{CR}=$ clinical remission; $\mathrm{ATO}=$ arsenic trioxide; ICE $=$ ifosfamide, carboplatin, etoposide; DOX = doxorubicin; I² VAd = ifosfamide, vincristine, dactinomycin $\mathrm{C}$. 


\section{DISCUSSION}

HGNET-BCOR is a recently described rare tumor entity of the central nervous system for which optimal treatment protocols are yet to be defined. Because patients with HGNET-BCOR were previously diagnosed as other entities, several treatment protocols have been attempted. To date, protocols for the treatment of CNSPNET, glioblastoma and ependymoma have been used, all of which have included high doses of chemotherapy and radiation. According to the available data on follow up, no protocol has been successful in the treatment of this tumor entity with most patients developing progressive disease [1]. A recent clinicopathologic and molecular characterization of 3 cases of HGNET-BCOR [35] confirmed the difficulty encountered in controlling this tumor entity using surgical resection of the primary tumor followed by radiation and chemotherapy. Here we show that the combination of conventional sarcoma-based chemotherapy, irradiation and ATO administration led to complete remission after extra-cerebral relapse with six months of progression-free survival.

Available microarray data suggest that the upregulation of the SHH pathway is a common feature of HGNET-BCOR. We have previously validated the activation of the SHH pathway in P1 [4] and in this work in P2. Thus, a targeted therapy against this pathway is of interest for HGNET-BCOR patients. The therapeutic effect of the SMO inhibitor itraconazole has been recently discussed in one HGNET-BCOR female pediatric patient [35]. Unfortunately no in vitro data on the sensitivity of the HGNET-BCOR cells to itraconazole were available for that patient. Moreover, SMO inhibition causes permanent defects in bone structure in young mice, and its use in young children has to be carefully considered with respect to long-term toxicities [36]. Our data suggest a partially SMO-independent GLI transcriptional activity in the PhKh1 cells which has been described in other tumor entities. A possible mechanism for the SMO-independent activation of GLI could rely on the presence of the ITD. BCOR enhances BCL6-mediated transcriptional repression by interacting with histone deacetylases (HDAC) [37]. Moreover, BCOR forms a complex with Polycomb proteins and can act as an epigenetic repressor [38]. BCOR wt can repress the expression of GLII and GLI2 [39]. The ITD is localized in a region required for the binding to the Polycomb complex and required for the full activity of BCOR [31]. Thus the ITD may interfere with the repressor function of BCOR leading to the upregulation of GLII and GLI2. This hypothesis has to be

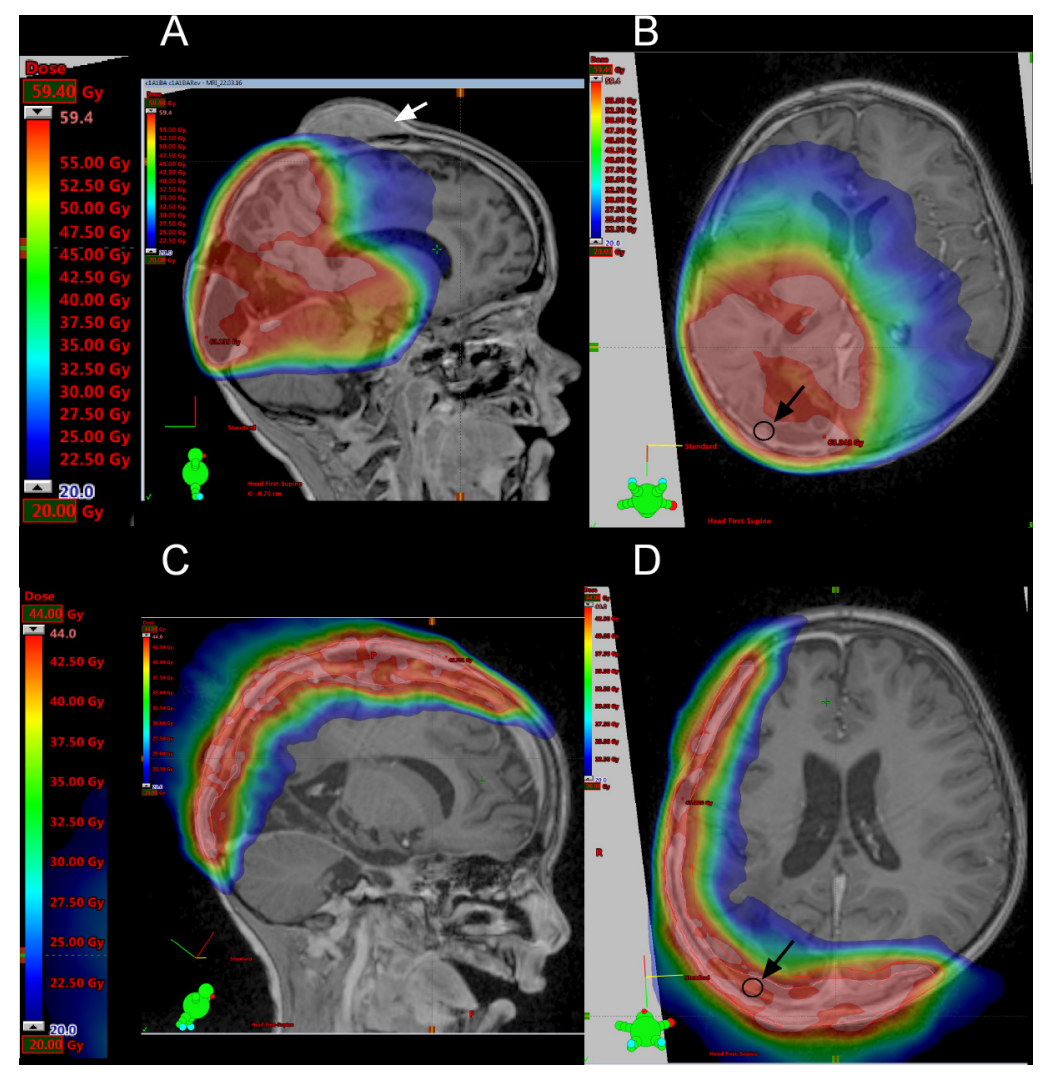

Figure 4: Irradiation fields used in the treatment protocol. (A-B) MRI showing the irradiation field used in the first line therapy. The intensity of the irradiation field is shown in color. The gradation is from 20 Gy (blue) to 59.4 Gy (red). (C-D) MRI showing the irradiation field used in the targeted therapy. The gradation is from $20 \mathrm{~Gy}$ (blue) to $44 \mathrm{~Gy}$ (red). The white arrow indicates a skull metastasis, the dark circle and the dark arrow indicate a dural lesion. 

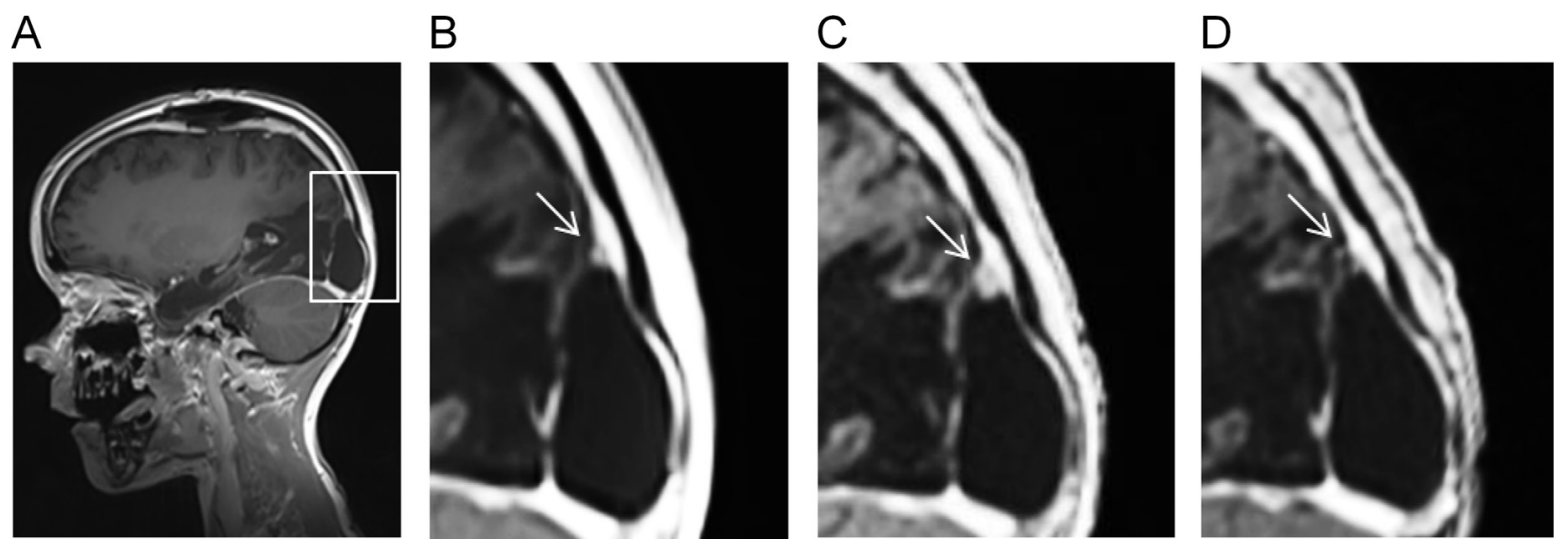

Figure 5: The target lesion is sensitive to the targeted therapy. MRI showing the dural lesion developed under the first line therapy (A-B), before the start of the targeted therapy (C) and at the time of CR (D).
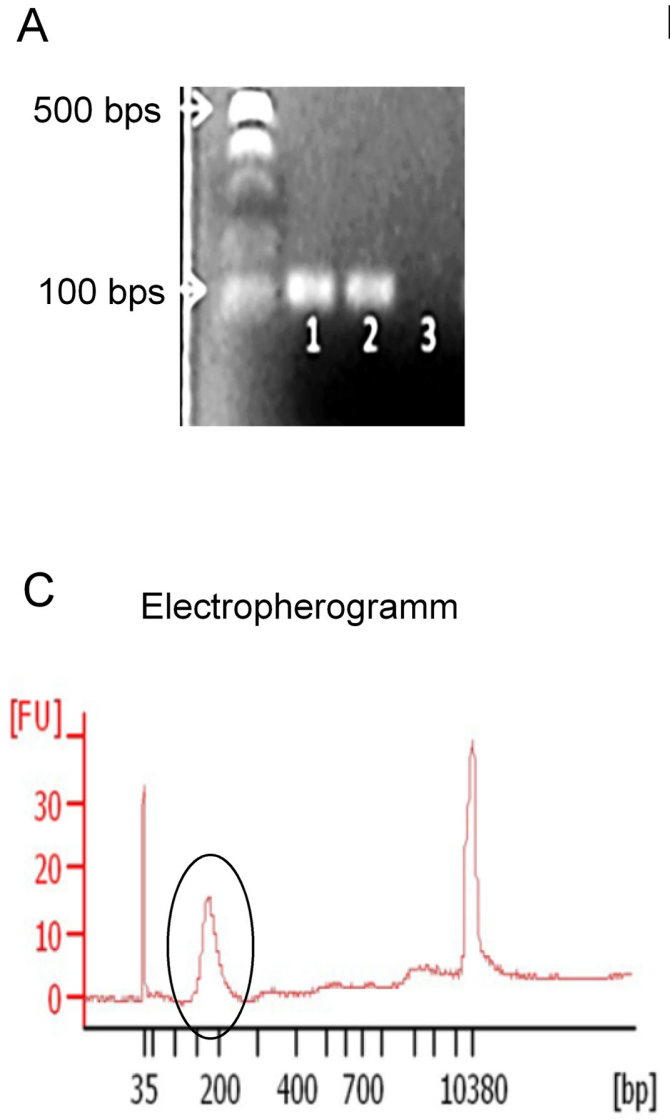

B
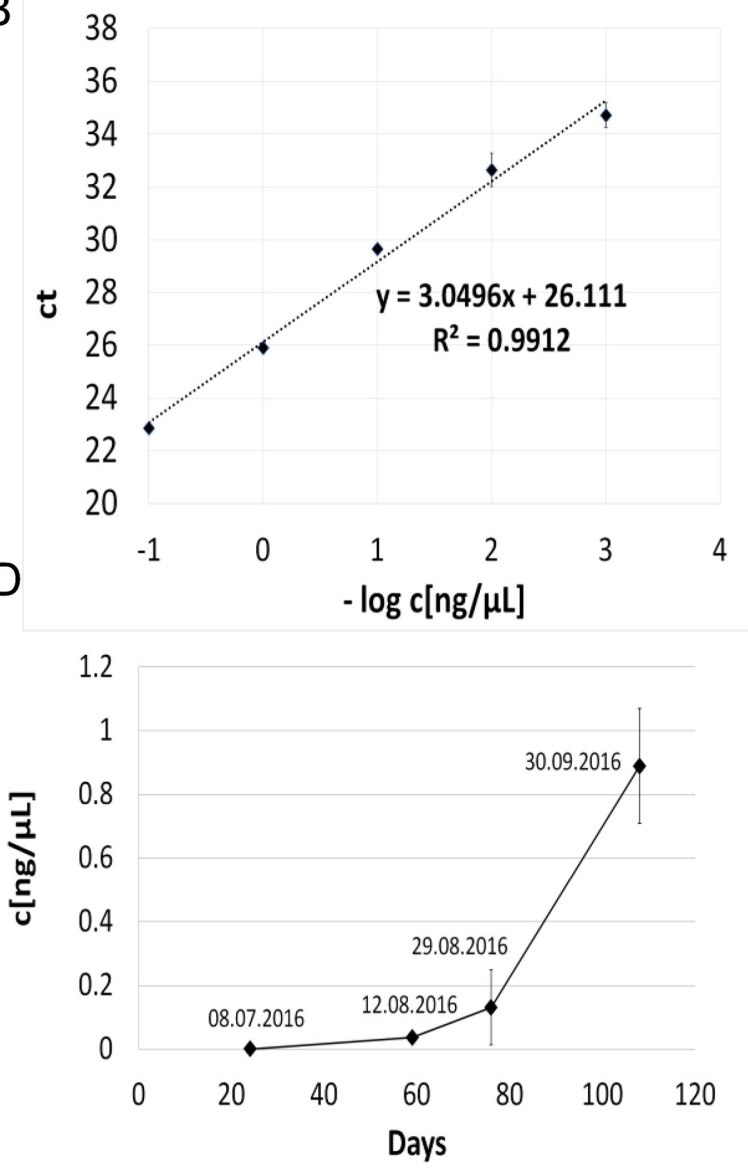

Figure 6: The BCOR ITD is maintained in the systemic metastases of P1. (A) BCOR ITD specific primers were used for PCR analysis of the genomic DNA extracted from the primary tumor (lane 1), a metastasis (lane 2) and the blood (lane 3) of P1. The expected product of $B C O R$ ITD is 117 bps. (B) The genomic DNA extracted from the primary tumor was diluted at different concentrations. The $-\log$ of the concentration in $\mathrm{ng} / \mu \mathrm{l}$ is shown on the $\mathrm{x}$-axis. The threshold cycle (ct) is shown on the $\mathrm{y}$ axis. The slope of the standard curve was used to calculate the efficiency of the primers. (C) The size of the isolated ctDNA was analyzed using a Bioanalyzer. The y axis shows the signal intensity (FU) and the $\mathrm{x}$ axis the size distribution in bps. The circle indicates the purified ctDNA. (D) The concentration of the ctDNA was calculated based on the standard curve in B and reported as ng of ctDNA per $\mu \mathrm{l}$ of purified ctDNA (ng/ $\mu \mathrm{l}$ ) on the $\mathrm{y}$ axis. The $\mathrm{x}$ axis report the days of the plasma collection with respect to the time of the complete remission as assessed by MRI $(\mathrm{x}=0)$. To facilitate the comparison with the sketch in Figure 3, the datum of the plasma collection is also reported. 
validated but it is in line with the observed upregulation of GLI transcripts in clear cell sarcoma of the kidney which also express the BCOR ITD [2]. Thus, targeting the SHH pathway downstream of SMO at the level of the GLI transcripts using ATO is a particularly attractive approach in HGNET-BCOR. Here we show that ATO reduced the transcription of GLI target genes in a primary culture of HGNET-BCOR. In APL, ATO triggers the degradation of the PML-RAR $\alpha$ fusion protein, probably by binding to a cysteine-rich region [40]. However, no cysteine-rich regions are created by the presence of the ITD. Thus, the effect of ATO on GLI in HGNET-BCOR is probably direct and not via BCOR. Indeed ATO has been shown to reduce GLI activity by direct binding to GLI proteins [7]. Moreover, the upregulation of GLI itself seemed to be responsible for the ineffectiveness of conventional chemotherapy [41, 42] and earlier studies demonstrated additive effects of ATO with conventional chemotherapeutic agents such as cisplatin, adriamycin, and etoposide $[43,44]$. The down-regulation of GLI transcription factors via ATO to sensitize HGNET-BCOR cells to conventional chemotherapy, particularly to the sarcoma-based chemotherapy applied in the relapse protocol warrants further investigation.

The radiosensitivity of HGNET-BCOR is suggested by the growth of the skull metastases outside of the high dosage area. The relevance of postoperative craniospinal irradiation in patients suffering from CNS HGNET-BCOR has been recently discussed [35]. However, irradiation alone was not able to control the progression of the disease in P1. Indeed, the target lesion developed in a region that was irradiated with 59.4 Gy during the irradiation of the primary tumor suggesting the necessity to add radiation sensitizers, like ATO, to the treatment protocol. Recent reports have shown synergistic radio-sensitizing effects by concomitant treatment with ionizing radiation and ATO in a variety of tumor cell lines in vitro [45-47] as well as in tumor xenografts $[48,49]$. Our work indicates additive cytotoxic effects of radiation and ATO on the clonogenic survival of $\mathrm{PhKh} 1$ cells in vitro at an ATO concentration lower than in the available literature mentioned above. Our finding of additive cytotoxicity of radiation and ATO in a HGNET-BCOR cell-strain offers a rationale for concomitant treatment regimens to achieve a higher tumor response and reduce radiation dosage during whole-brain radiotherapy to lower the risks for radiation-related late adverse effects in pediatric patients. Considering acute and long-term toxicity of arsenic agents, we observed no severe adverse effects during and after the six-month period with a cumulative dose of $18.4 \mathrm{mg} / \mathrm{kg}$. Notably, the good tolerance of continuous treatment with oral ATO together with no need to hospitalize the patient besides regular monitoring of the arsenic concentration might be beneficial for pediatric patients.

ATO at a concentration of $1.5 \mu \mathrm{M}$ effectively reduced the growth of the PhKh1 cells, and the growth was completed inhibited if the cells were cultivated in the presence of $3 \mu \mathrm{M}$ ATO. A peak level of $5.54 \mu \mathrm{M}$ to 7.30 $\mu \mathrm{M}$ plasma arsenic can be achieved in APL patients with an acceptable safety profile [12]. Arsenic can penetrate the CNS of APL patients with a mean concentration of $199 \mathrm{nM}$ [50]. This concentration can be increased to $0.5 \mu \mathrm{M}$ by the addition of mannitol [51]. Moreover, higher concentration of ATO is known to accumulate in tumor tissues compared
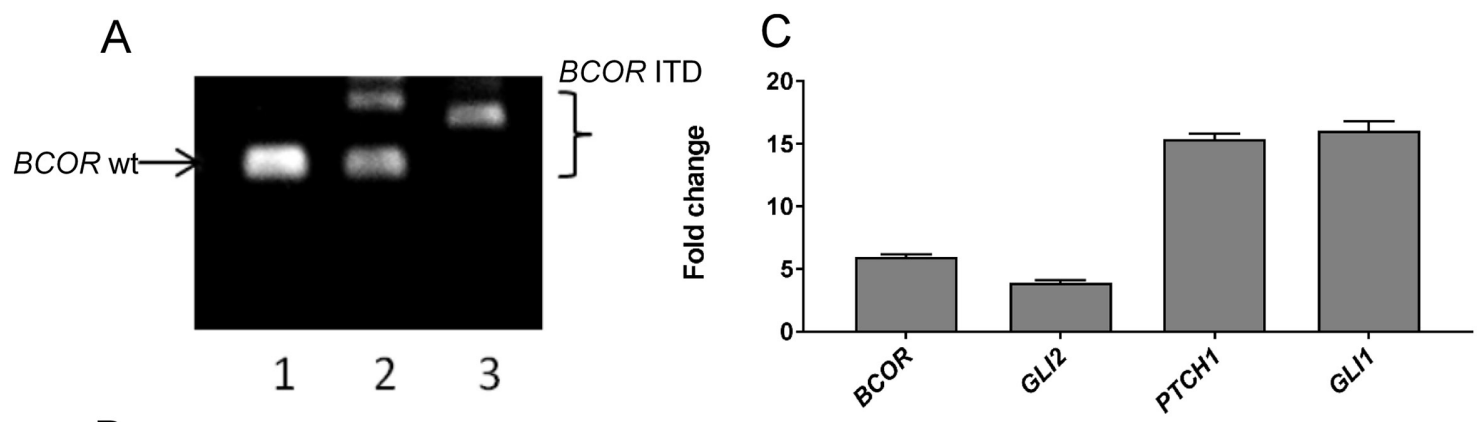

B

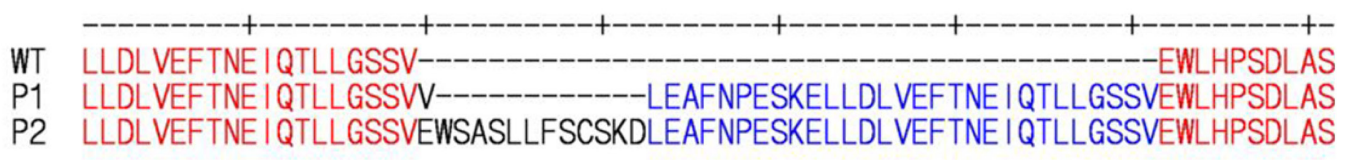

Figure 7: The SHH pathway is upregulated in an additional CNS HGNET-BCOR case. (A) The sequence of exon 15 of $B C O R$ was analyzed by PCR in the genomic DNA extracted from the blood of P1 (lane 1), the primary tumor of P2 (lane 2) or from the primary tumor of P1 (lane 3). The sizes of the wt BCOR and of the BCOR ITDs are indicated. (B) Protein sequence of the BCOR allele of P2 carrying the ITD compared to the wild type BCOR and to the BCOR ITD detected in P1. (C) qRT-PCR analysis was performed using primers recognizing BCOR, GLI2, PTCH1 or GLI1. After normalization to the housekeeping gene HPRT1, the fold change of the expression of P2 with respect to P1 was calculated. Expression analysis was done in triplicates. Expression analysis was done on RNA extracted from FFPE material. 
to normal brain and the total concentration of ATO in the plasma or CSF may not reflect the true concentration in tumor tissue [52]. Importantly, 1.0 $\mu \mathrm{M}$ ATO showed little influence on the viability of cortical neurons [53] while we observed a radio-sensitizing of ATO already at a concentration of $0.5 \mu \mathrm{M}$. Thus, therapeutically meaningful and safe concentrations of arsenic in plasma and CNS can be achieved. With our protocol, we achieved a maximum arsenic concentration of $645 \mathrm{nM}$ in plasma and of $129 \mathrm{nM}$ in CSF, a concentration that was below the $\mathrm{IC}_{50}$. The low levels of arsenic achieved in this study could explain why the patient progressed under the targeted therapy after the initial response. Of course, no conclusion can be drawn from only one case but efforts could be undertaken in future cases to increase the ATO concentration for example by a daily ATO administration, possibly orally and to understand the pharmacokinetic and pharmacodynamic of ATO in HGNET-BCOR patients.

Tumor evolution escaping conventional and targeted therapy is a major limitation for the successful treatment of cancer. We were able to detect the BCOR ITD in the ctDNA isolated from the peripheral blood of the patient P1, at the time systemic metastases developed, demonstrating that despite the use of aggressive conventional and targeted therapy, the tumor can still carry the alteration detected at the time of the first diagnosis. This finding underlines the relevance of the ITD in the biology of this tumor. Because HGNET-BCOR patients can develop systemic metastases, peripheral blood analysis for circulating $B C O R$-ITD DNA could help in the early identification of high-risk patients.

The PhKh1 primary tumor cells resistant to ATO overexpressed transcripts coding for the molecular chaperones CLU and ANXA1. Chaperones are expressed in response to chemotherapy and play a crucial role in maintaining the stability and activity of numerous signaling proteins required in the tumor development, including the processes of metastases formation. Therefore chaperons are considered as important targets in cancer treatment [54]. Down-regulating CLU or ANXA1 expression may represent an attractive therapeutic strategy to enhance the effect of ATO treatment. Second-generation antisense oligodeoxynucleotide designed to inhibit CLU are currently in late-stage clinical development [55]. The resistant cells also expressed CEMIP, a protein associated with cancer cell survival, migration and invasion. However, CEMIP has been reported to play roles in cancer cell proliferation and invasion either negatively or positively [56] and its role in the tumor progression of HGNET-BCOR remains to be clarified. Because tumor material of the metastases developed under the targeted therapy was not available, we were not able to proof if the molecular chaperones and CEMIP were overexpressed in vivo and contributed in fact to the development of the metastases.

P2 remained free of disease 20 months after the first diagnosis. The presence of the wt BCOR allele in the P2 patient (female) could be related to the better prognosis compared to the $\mathrm{P} 1$ patient (male). Because $B C O R$ is on the $\mathrm{X}$ chromosome, male patients have only the copy with the ITD while female patients can still carry the wt allele, as described in the two patients in our study. It would be interesting to analyze if female patients with a relapse loss the wt $B C O R$ allele. Intriguingly, all tumor entities carrying the $B C O R$ ITD show a male predominance [35]. However, there are not enough published outcome data to conclude on a possible gender-related prognosis in HGNET-BCOR.

In conclusion, our results present evidence that the targeting of GLI transcripts via ATO, in combination with radiotherapy in addition to conventional back-bone chemotherapy is a promising approach that warrants validation in a clinical study.

\section{MATERIALS AND METHODS}

\section{Patient primary tissue samples, CSF, peripheral blood and cell lines}

Clinical history of $\mathrm{P} 1$, tumor samples and the shortterm primary cell culture (PhKh1) isolated from this patient have already been described [4]. Briefly, sample 123 was derived from the primary tumor of P1, sample 167 from a metastasis from the same patient and sample 129 was isolated from a medulloblastoma of the WNT subtype. To monitor the concentration of arsenic under targeted therapy with ATO, plasma and CSF from P1 were collected at different time points. Surplus plasma was used for the extraction of ctDNA. This study was performed in agreement with the declaration of Helsinki. In accordance with the ethics committee of Rhineland-Palatinate, the patient's parents agreed with the scientific use of the surplus material. Informed consent of the patient's parents for the targeted therapy was obtained. No further approval of the medical ethics committee was required as only one patient was involved.

P2 is a female infant who presented at the age of four years and nine months with a posterior fossa mass without leptomeningeal dissemination. The tumor was completely removed and after initial radiological and histological assessment was diagnosed as medulloblastoma. However, additional immunohistochemistry was performed during consultative pathologic review that showed negative synaptophysin staining and positive OLIG2 staining in a large fraction of the tumor cells, findings that are not typical for medulloblastoma. The CNS HGNET-BCOR diagnosis in P2 was based on targeted next-generation sequencing results from the UCSF500 Cancer Panel, which we have previously described [57], that detected an internal tandem duplication in exon 15 of the $B C O R$ gene and absence of genetic alterations that are commonly seen in medulloblastomas. Formalin-fixed and paraffinembedded (FFPE) material derived from the primary 
tumor was used for the analysis. Consent to publish details of the therapy and the results of the molecular analysis was obtained from the parents and approved by the patient's hospital Institutional Review Board (IRB).

\section{Nucleic acid extraction}

DNA was extracted using the Gentra Puregene Blood Kit or the QIAamp DNA FFPE (Qiagen, Hilden, Germany). RNA extraction was performed using the RNeasy Mini Kit or the RNeasy FFPE Kit for FFPE material (Qiagen). RNA was converted to cDNA using PrimeScript RT Reagent Kit with gDNA Eraser (Takara Bio Europe, Saint-Germain-en-Laye, France). Quality control was performed using a 2100 Bioanalyzer (Agilent Technologies, Waldbronn, Germany). Due to expected low quality of the RNA extracted from FFPE, the protocol for cDNA synthesis was changed. Instead of utilizing the RT Primer Mix that is included in the kit, we used gene-specific reverse primers and the reaction samples were incubated for 60 minutes at 42 degrees Celsius instead of 15 minutes at 37 degrees Celsius. ctDNA was isolated from $1.5 \mathrm{ml}$ plasma using the QIAamp Circulating Nucleic Acid Kit (Qiagen). ctDNA was eluted in $20 \mu \mathrm{l}$ water and analyzed using a 2100 Bioanalyzer. The $B C O R$ ITD was detected with following primers: 5'- GGCTCCTCTGTAGTCCTGGA and 5'GGGGTGGAGCCACTCTACA.

\section{RT-PCR and qRT-PCR}

RNA was converted to cDNA by using PrimeScript RT Reagent Kit with gDNA Eraser (Takara Bio Europe, Saint-Germain-en-Laye, France). qRT-PCR was performed using the LightCycler 480 II Detection System and Software (Applied Biosystems, Darmstadt, Germany) with KAPA SYBR FAST LightCycler 480 Kit (PeqLab, Erlangen, Germany). The sequence of the primers can be found in the Supplementary Materials. After normalization to the housekeeping gene HPRT1, the relative quantification value was expressed as $2^{-\Delta \Delta \mathrm{Ct}}$. The calibrator was calculated as the maximal number of cycles used in the PCR (40) minus the mean of the HPRT1 Ct values, resulting in a value of 19.

\section{DNA sequencing and TA cloning}

The coding exons of SMO were amplified by PCR using $50 \mathrm{ng}$ of DNA. The primers were as described in [4]. The region containing the $B C O R$ ITD was amplified using primers 5'-GGAAATTGTCACCATTGCAGAGG and 5'-TGTACATGGTGGGTCCAGCT. Sanger Sequencing was performed as previously described [4]. TA cloning was performed by TA Cloning ${ }^{\circledR}$ Kit with pCR ${ }^{\text {TM}} 2.1$ Vector and One Shot ${ }^{\circledR}$ TOP10F' Chemically Competent E. coli (Thermo Scientific, Dreieich, Germany). The TA cloning method takes advantage of the terminal transferase activity of some DNA polymerases adding a 3'-A overhang to each end of the PCR product. This makes it possible to clone this PCR product directly into a linearized cloning vector with single, 3'-T overhangs. Clones were analyzed by Sanger sequencing.

\section{Cellular proliferation assays}

Itraconazole and vismodegib (both Selleckchem, Houston, USA) were dissolved in DMSO at a concentration of $20 \mathrm{mM}$ and $50 \mathrm{mM}$, respectively. ATO (Sigma-Aldrich, Taufkirchen, Germany) was prepared as described previously [4]. Cells were plated in triplicates at a density of 5,000 cells/well in a 96-well plate. Itraconazole and vismodegib at varying concentrations or vehicle alone were added to the cells. Viable cells were quantified after three days using the cell proliferation reagent WST-1 (Roche, Mannheim, Germany). Doseresponse curves were plotted to determine the halfmaximal inhibitory concentration $\left(\mathrm{IC}_{50}\right)$ using the GraphPad Prism v.5 (GraphPad Software, San Diego CA, USA). For long-term experiments, 5,000 cells were plated in triplicates and incubated with different concentrations of itraconazole, vismodegib, ATO or vehicle alone.

\section{Clonogenic assay}

Survival curves of PhKh1 cells were generated after X-ray exposure or after concomitant treatment with radiation and $0.5 \mu \mathrm{M}$ ATO using an in-vitro clonogenic assay [58]. Cells were irradiated with doses of 0,2, 4 and 8 Gy and seeded at densities of $5 \times 10^{3}, 1 \times 10^{4}, 2 \times$ $10^{4}$ and $3 \times 10^{4}$ per well, respectively. Three independent experiments were performed. ATO was added after 24 hours and cells were exposed to X-rays $(140 \mathrm{kV})$ at room temperature using the D3150 X-ray Therapy System (Gulmay Medical Ltd., UK) at a dose rate of $3.62 \mathrm{~Gy} /$ min or were mock treated, i.e., kept for the same time in the radiation device control room. Cells were incubated for 14 days to allow colony formation, stained with $0.25 \%$ crystal violet and colonies containing $\geq 50$ cells were counted as survivors. Plating efficiency (PE) was assessed as the ratio of the number of colonies counted as survivors to the number of cells seeded. The surviving fraction (SF) was calculated as follows: $\mathrm{SF}=$ colonies counted/(cells seeded x PE), taking into consideration the individual PE.

\section{RNA sequencing}

Libraries preparation, sequencing and Transcripts per Kilobase Million (TPM) calculation was as described previously [4]. To identify genes associated with ATO resistance, we calculated the ratio of the expression between the TPM of the PhKh1 cells grown under ATO and of the PhKh1 cells grown under the vehicle alone and selected genes with a fold change $>20$. 


\section{Targeted therapy protocol}

Relapse treatment protocol of P1 combined conventional radio-chemotherapy with an individualized therapy approach using intravenous and oral ATO. As back-bone chemotherapy, we integrated several treatment elements from pediatric rhabdoid and soft-tissue sarcoma protocols (EURHAB; CWS-Guidance). In accordance with our previous and current results from the PhKh1 cell cultures [4] we added ATO as individualized therapy approach to the relapse treatment protocol, with concurrent irradiation to the skull metastases (44 Gy, 5x2Gy/week). For details see the results section.

\section{Arsenic concentration}

The total arsenic concentration in CSF and plasma was analyzed by a certified laboratory using inductively coupled plasma mass spectrometry (ICP-MS) (Medizinisches Labor Bremen, Bremen, Germany).

\section{Western blot analysis}

Nuclear extracts were generated as previously described [4]. GLI2 antibody was from LifeSpan BioSciences (Eching, Germany) and Lamin B antibody from Cell Signaling.

\section{Abbreviations}

APL: acute promyelocytic leukemia; ATO: arsenic trioxide, BCOR: BCL-6 co-repressor; CNS HGNETBCOR: high-grade neuroepithelial tumor of the central nervous system with BCOR alteration; ct: threshold cycle; ctDNA: circulating DNA; CR: complete remission; CSF: cerebrospinal fluid; DOX: doxorubicin; ICE: ifosfamide, carboplatin, etoposide; ITD: internal tandem duplication; $I^{2}$ VAd: ifosfamide, vincristine, dactinomycin C; PD: progressive disease; PE: Plating efficiency; TPM: Transcripts per Kilobase Million.

\section{Author contributions}

$\mathrm{CP}, \mathrm{AR}$ and JF conceived and designed the study; AR, HO, DS (David Samuel), GD, KW, FA, AW, MAA, OB, SE, NH, KEM, HS conceived the therapy protocols and provided clinical advice; DS (David Scharnhorst), DAS, LS, CS provided molecular analysis and pathological evaluation; OB, SE, NH, KEM, WW collected samples; CP, HO, AM, WW, MAB, HS, GS, DP participated in collection, analysis, and interpretation of the data; JF, AR, AW, MAB revised the manuscript; SZ, NL, NB, LR, HB performed experiments; CP prepared the draft; CP, HO, AM, SZ, GS, MAB prepared the figures; HO, AR, GD, KW, FA, DP and DS (David Samuel) helped write the manuscript. All authors read and approved the manuscript.

\section{ACKNOWLEDGMENTS}

We are grateful to the patients and families who contributed tumor tissue for the further study of this tumor entity. We also thank Jasmin Persch, Section of Pediatric Oncology, Children's Hospital, University Medical Center of the Johannes Gutenberg University Mainz, for the editing of the manuscript.

\section{CONFLICTS OF INTEREST}

The authors have declared no conflicts of interest.

\section{FUNDING}

This work has been supported by the Intramurals Funding Program of the Medical University of Mainz (no 2015_3_CPa to Claudia Paret).

\section{REFERENCES}

1. Sturm D, Orr BA, Toprak UH, Hovestadt V, Jones DT, Capper D, Sill M, Buchhalter I, Northcott PA, Leis I, Ryzhova M, Koelsche C, Pfaff E, et al. New brain tumor entities emerge from molecular classification of CNSPNETs. Cell. 2016; 164:1060-1072.

2. Roy A, Kumar V, Zorman B, Fang E, Haines KM, Doddapaneni H, Hampton OA, White S, Bavle AA, Patel NR, Eldin KW, John Hicks M, Rakheja D, et al. Recurrent internal tandem duplications of BCOR in clear cell sarcoma of the kidney. Nat Commun. 2015; 6:8891.

3. Kao YC, Sung YS, Zhang L, Huang SC, Argani P, Chung CT, Graf NS, Wright DC, Kellie SJ, Agaram NP, Ludwig K, Zin A, Alaggio R, et al. Recurrent BCOR internal tandem duplication and YWHAE-NUTM2B fusions in soft tissue undifferentiated round cell sarcoma of infancy: overlapping genetic features with clear cell sarcoma of kidney. Am J Surg Pathol. 2016; 40:1009-1020.

4. Paret C, Theruvath J, Russo A, Kron B, El Malki K, Lehmann N, Wingerter A, Neu MA, Gerhold-Ay A, Wagner W, Sommer C, Pietsch T, Seidmann L, Faber J. Activation of the basal cell carcinoma pathway in a patient with CNS HGNET-BCOR diagnosis: consequences for personalized targeted therapy. Oncotarget. 2016; 7:83378-83391. https:// doi.org/10.18632/oncotarget.13092.

5. Lauth M, Toftgard R. Non-canonical activation of GLI transcription factors: implications for targeted anti-cancer therapy. Cell Cycle. 2007; 6:2458-2463.

6. Fellner C. Vismodegib (erivedge) for advanced Basal cell carcinoma. P T. 2012; 37:670-682.

7. Beauchamp EM, Ringer L, Bulut G, Sajwan KP, Hall MD, Lee YC, Peaceman D, Ozdemirli M, Rodriguez O, Macdonald TJ, Albanese C, Toretsky JA, Uren A. Arsenic trioxide inhibits human cancer cell growth and tumor 
development in mice by blocking Hedgehog/GLI pathway. J Clin Invest. 2011; 121:148-160.

8. Fox E, Razzouk BI, Widemann BC, Xiao S, O'Brien M, Goodspeed W, Reaman GH, Blaney SM, Murgo AJ, Balis FM, Adamson PC. Phase 1 trial and pharmacokinetic study of arsenic trioxide in children and adolescents with refractory or relapsed acute leukemia, including acute promyelocytic leukemia or lymphoma. Blood. 2008; 111:566-573.

9. Rimkus TK, Carpenter RL, Qasem S, Chan M, Lo HW. Targeting the sonic hedgehog signaling pathway: review of smoothened and GLI inhibitors. Cancers (Basel). 2016.

10. Ferruzzi P, Mennillo F, De Rosa A, Giordano C, Rossi M, Benedetti G, Magrini R, Pericot Mohr G, Miragliotta $\mathrm{V}$, Magnoni L, Mori E, Thomas R, Tunici $\mathrm{P}$, et al. In vitro and in vivo characterization of a novel Hedgehog signaling antagonist in human glioblastoma cell lines. Int J Cancer. 2012; 131:E33-44.

11. Kim J, Aftab BT, Tang JY, Kim D, Lee AH, Rezaee M, Kim J, Chen B, King EM, Borodovsky A, Riggins GJ, Epstein EH Jr, Beachy PA, et al. Itraconazole and arsenic trioxide inhibit Hedgehog pathway activation and tumor growth associated with acquired resistance to smoothened antagonists. Cancer Cell. 2013; 23:23-34.

12. Shen ZX, Chen GQ, Ni JH, Li XS, Xiong SM, Qiu QY, Zhu J, Tang W, Sun GL, Yang KQ, Chen Y, Zhou L, Fang ZW, et al. Use of arsenic trioxide (As2O3) in the treatment of acute promyelocytic leukemia (APL): II. Clinical efficacy and pharmacokinetics in relapsed patients. Blood. 1997; 89:3354-3360.

13. Rhee HJ, Kim GY, Huh JW, Kim SW, Na DS. Annexin $\mathrm{I}$ is a stress protein induced by heat, oxidative stress and a sulfhydryl-reactive agent. Eur J Biochem. 2000; 267:3220-3225.

14. Shiota M, Zoubeidi A, Kumano M, Beraldi E, Naito S, Nelson CC, Sorensen PH, Gleave ME. Clusterin is a critical downstream mediator of stress-induced YB-1 transactivation in prostate cancer. Mol Cancer Res. 2011; 9:1755-1766.

15. Lin HY, Michtalik HJ, Zhang S, Andersen TT, Van Riper DA, Davies KK, Ermak G, Petti LM, Nachod S, Narayan AV, Bhatt N, Crawford DR. Oxidative and calcium stress regulate DSCR1 (Adapt78/MCIP1) protein. Free Radic Biol Med. 2003; 35:528-539.

16. Lewerenz J, Hewett SJ, Huang Y, Lambros M, Gout PW, Kalivas PW, Massie A, Smolders I, Methner A, Pergande M, Smith SB, Ganapathy V, Maher P. The cystine/glutamate antiporter system $\mathrm{x}(\mathrm{c})(-)$ in health and disease: from molecular mechanisms to novel therapeutic opportunities. Antioxid Redox Signal. 2013; 18:522-555.

17. Berns K, Sonnenblick A, Gennissen A, Brohee S, Hijmans EM, Evers B, Fumagalli D, Desmedt C, Loibl S, Denkert C, Neven P, Guo W, Zhang F, et al. Loss of ARID1A activates ANXA1, which serves as a predictive biomarker for trastuzumab resistance. Clin Cancer Res. 2016; 22:5238-5248.

18. Wu N, Liu S, Guo C, Hou Z, Sun MZ. The role of annexin A3 playing in cancers. Clin Transl Oncol. 2013; 15:106-110.

19. Tsai HC, Huang CY, Su HL, Tang CH. CTGF increases drug resistance to paclitaxel by upregulating survivin expression in human osteosarcoma cells. Biochim Biophys Acta. 2014; 1843:846-854.

20. Zellweger T, Miyake H, July LV, Akbari M, Kiyama S, Gleave ME. Chemosensitization of human renal cell cancer using antisense oligonucleotides targeting the antiapoptotic gene clusterin. Neoplasia. 2001; 3:360-367.

21. Evensen NA, Kuscu C, Nguyen HL, Zarrabi K, Dufour A, Kadam P, Hu YJ, Pulkoski-Gross A, Bahou WF, Zucker S, Cao J. Unraveling the role of KIAA1199, a novel endoplasmic reticulum protein, in cancer cell migration. J Natl Cancer Inst. 2013; 105:1402-1416.

22. Boehme KA, Nitsch J, Riester R, Handgretinger R, Schleicher SB, Kluba T, Traub F. Arsenic trioxide potentiates the effectiveness of etoposide in Ewing sarcomas. Int J Oncol. 2016; 49:2135-2146.

23. Boehme KA, Zaborski JJ, Riester R, Schweiss SK, Hopp U, Traub F, Kluba T, Handgretinger R, Schleicher SB. Targeting hedgehog signalling by arsenic trioxide reduces cell growth and induces apoptosis in rhabdomyosarcoma. Int J Oncol. 2016; 48:801-812.

24. Kerl K, Moreno N, Holsten T, Ahlfeld J, Mertins J, Hotfilder M, Kool M, Bartelheim K, Schleicher S, Handgretinger R, Schuller U, Meisterernst M, Fruhwald MC. Arsenic trioxide inhibits tumor cell growth in malignant rhabdoid tumors in vitro and in vivo by targeting overexpressed Gli1. Int $\mathrm{J}$ Cancer. 2014; 135:989-995.

25. Cohen KJ, Gibbs IC, Fisher PG, Hayashi RJ, Macy ME, Gore L. A phase I trial of arsenic trioxide chemoradiotherapy for infiltrating astrocytomas of childhood. Neuro Oncol. 2013; 15:783-787.

26. Kumana CR, Au WY, Lee NS, Kou M, Mak RW, Lam CW, Kwong YL. Systemic availability of arsenic from oral arsenic-trioxide used to treat patients with hematological malignancies. Eur J Clin Pharmacol. 2002; 58:521-526.

27. Torka P, Al Ustwani O, Wetzler M, Wang ES, Griffiths EA. Swallowing a bitter pill-oral arsenic trioxide for acute promyelocytic leukemia. Blood Rev. 2016; 30:201-211.

28. Au WY, Kwong YL. Arsenic trioxide: safety issues and their management. Acta Pharmacol Sin. 2008; 29:296-304.

29. Au WY, Tam S, Fong BM, Kwong YL. Determinants of cerebrospinal fluid arsenic concentration in patients with acute promyelocytic leukemia on oral arsenic trioxide therapy. Blood. 2008; 112:3587-3590.

30. Mouliere F, Robert B, Arnau Peyrotte E, Del Rio M, Ychou M, Molina F, Gongora C, Thierry AR. High fragmentation characterizes tumour-derived circulating DNA. PLoS One. 2011; 6:e23418. 
31. Junco SE, Wang R, Gaipa JC, Taylor AB, Schirf V, Gearhart MD, Bardwell VJ, Demeler B, Hart PJ, Kim CA. Structure of the polycomb group protein PCGF1 in complex with BCOR reveals basis for binding selectivity of PCGF homologs. Structure. 2013; 21:665-671.

32. Cohen BH, Geyer JR, Miller DC, Curran JG, Zhou T, Holmes E, Ingles SA, Dunkel IJ, Hilden J, Packer RJ, Pollack IF, Gajjar A, Finlay JL, et al. Pilot study of intensive chemotherapy with peripheral hematopoietic cell support for children less than 3 years of age with malignant brain tumors, the CCG-99703 phase I/II study. A report from the Children's Oncology Group. Pediatr Neurol. 2015; 53:31-46.

33. Dhall G, Grodman H, Ji L, Sands S, Gardner S, Dunkel IJ, McCowage GB, Diez B, Allen JC, Gopalan A, Cornelius AS, Termuhlen A, Abromowitch M, et al. Outcome of children less than three years old at diagnosis with nonmetastatic medulloblastoma treated with chemotherapy on the "Head Start" I and II protocols. Pediatr Blood Cancer. 2008; 50:1169-1175.

34. Lafay-Cousin L, Smith A, Chi SN, Wells E, Madden J, Margol A, Ramaswamy V, Finlay J, Taylor MD, Dhall G, Strother D, Kieran MW, Foreman NK, et al. Clinical, pathological, and molecular characterization of infant medulloblastomas treated with sequential high-dose chemotherapy. Pediatr Blood Cancer. 2016; 63:1527-1534.

35. Appay R, Macagno N, Padovani L, Korshunov A, Kool M, Andre N, Scavarda D, Pietsch T, Figarella-Branger D. HGNET-BCOR tumors of the cerebellum: clinicopathologic and molecular characterization of 3 cases. Am J Surg Pathol. 2017.

36. Kimura H, Ng JM, Curran T. Transient inhibition of the Hedgehog pathway in young mice causes permanent defects in bone structure. Cancer Cell. 2008; 13:249-260.

37. Huynh KD, Fischle W, Verdin E, Bardwell VJ. BCoR, a novel corepressor involved in BCL-6 repression. Genes Dev. 2000; 14:1810-1823.

38. Gearhart MD, Corcoran CM, Wamstad JA, Bardwell VJ. Polycomb group and SCF ubiquitin ligases are found in a novel BCOR complex that is recruited to BCL6 targets. Mol Cell Biol. 2006; 26:6880-6889.

39. Tiberi L, Bonnefont J, van den Ameele J, Le Bon SD, Herpoel A, Bilheu A, Baron BW, Vanderhaeghen P. A BCL6/BCOR/SIRT1 complex triggers neurogenesis and suppresses medulloblastoma by repressing Sonic Hedgehog signaling. Cancer Cell. 2014; 26:797-812.

40. Chen SJ, Zhou GB, Zhang XW, Mao JH, de The H, Chen Z. From an old remedy to a magic bullet: molecular mechanisms underlying the therapeutic effects of arsenic in fighting leukemia. Blood. 2011; 117:6425-6437.

41. Satheesha S, Manzella G, Bovay A, Casanova EA, Bode PK, Belle R, Feuchtgruber S, Jaaks P, Dogan N, Koscielniak E, Schafer BW. Targeting hedgehog signaling reduces selfrenewal in embryonal rhabdomyosarcoma. Oncogene. 2016; 35:2020-2030.
42. Zhang L, Song R, Gu D, Zhang X, Yu B, Liu B, Xie J. The role of GLI1 for 5-Fu resistance in colorectal cancer. Cell Biosci. 2017; 7:17.

43. Du YH, Ho PC. Arsenic compounds induce cytotoxicity and apoptosis in cisplatin-sensitive and -resistant gynecological cancer cell lines. Cancer Chemother Pharmacol. 2001; 47:481-490.

44. Uslu R, Sanli UA, Sezgin C, Karabulut B, Terzioglu E, Omay SB, Goker E. Arsenic trioxide-mediated cytotoxicity and apoptosis in prostate and ovarian carcinoma cell lines. Clin Cancer Res. 2000; 6:4957-4964.

45. Chiu HW, Chen YA, Ho SY, Wang YJ. Arsenic trioxide enhances the radiation sensitivity of androgen-dependent and -independent human prostate cancer cells. PLoS One. 2012; 7:e31579.

46. Chiu HW, Lin W, Ho SY, Wang YJ. Synergistic effects of arsenic trioxide and radiation in osteosarcoma cells through the induction of both autophagy and apoptosis. Radiat Res. 2011; 175:547-560.

47. Ho SY, Chen WC, Chiu HW, Lai CS, Guo HR, Wang YJ. Combination treatment with arsenic trioxide and irradiation enhances apoptotic effects in U937 cells through increased mitotic arrest and ROS generation. Chem Biol Interact. 2009; 179:304-313.

48. Ning S, Knox SJ. Increased cure rate of glioblastoma using concurrent therapy with radiotherapy and arsenic trioxide. Int J Radiat Oncol Biol Phys. 2004; 60:197-203.

49. Chun YJ, Park IC, Park MJ, Woo SH, Hong SI, Chung HY, Kim TH, Lee YS, Rhee CH, Lee SJ. Enhancement of radiation response in human cervical cancer cells in vitro and in vivo by arsenic trioxide (As2O3). FEBS Lett. 2002; 519:195-200.

50. Kiguchi T, Yoshino Y, Yuan B, Yoshizawa S, Kitahara T, Akahane D, Gotoh M, Kaise T, Toyoda H, Ohyashiki K. Speciation of arsenic trioxide penetrates into cerebrospinal fluid in patients with acute promyelocytic leukemia. Leuk Res. 2010; 34:403-405.

51. Wang H, Cao F, Li J, Li L, Li Y, Shi C, Lan W, Li D, Zhao H, Zhang Y, Zhang Z, Liu X, Meng R, et al. Arsenic trioxide and mannitol for the treatment of acute promyelocytic leukemia relapse in the central nervous system. Blood. 2014; 124:1998-2000.

52. Zhuang G, Zhou Y, Lu H, Lu W, Zhou M, Wang Y, Tan M. Concentration of rare earth elements, As, and Th in human brain and brain tumors, determined by neutron activation analysis. Biol Trace Elem Res. 1996; 53:45-49.

53. Zhou J, Meng R, Sui X, Li W, Yang B. Various tolerances to arsenic trioxide between human cortical neurons and leukemic cells. Sci China C Life Sci. 2006; 49:567-572.

54. Calderwood SK, Murshid A. Molecular chaperone accumulation in cancer and decrease in Alzheimer's disease: the potential roles of HSF1. Front Neurosci. 2017; 11:192.

55. Zielinski R, Chi KN. Custirsen (OGX-011): a secondgeneration antisense inhibitor of clusterin in development for the treatment of prostate cancer. Future Oncol. 2012; 8:1239-1251. 
56. Tiwari A, Schneider M, Fiorino A, Haider R, Okoniewski MJ, Roschitzki B, Uzozie A, Menigatti M, Jiricny J, Marra G. Early insights into the function of KIAA1199, a markedly overexpressed protein in human colorectal tumors. PLoS One. 2013; 8:e69473.

57. Kline CN, Joseph NM, Grenert JP, van Ziffle J, Talevich E, Onodera C, Aboian M, Cha S, Raleigh DR, Braunstein
S, Torkildson J, Samuel D, Bloomer M, et al. Targeted next-generation sequencing of pediatric neuro-oncology patients improves diagnosis, identifies pathogenic germline mutations, and directs targeted therapy. Neuro Oncol. 2017; 19:699-709.

58. Puck TT, Marcus PI. Action of x-rays on mammalian cells. J Exp Med. 1956; 103:653-666. 